\title{
Comportamento de vacas da raça holandesa em pastagem manejada sob princípios agroecológicos
}

\author{
Behaviour of holstein cows in pasture managed under agroecology principles
}

\author{
Clair Jorge Olivo ${ }^{1}$ Marinês Fátima Sobczak ${ }^{2}$ Pablo Santini Charão $^{2}$ \\ Arli Heimerdinger ${ }^{2}$ José Henrique Souza da Silva $^{3}$
}

\section{RESUMO}

O trabalho foi realizado na Universidade Federal de Santa Maria - RS, e teve como objetivo avaliar o comportamento de vacas em lactação da raça Holandesa em pastagem constituída por capim-elefante (Pennisetum purpureum Schum.) e aveia preta (Avena strigosa). Foram feitas quatro avaliações (caracterizando o período hibernal) nos dias 12/06, 17/07, 25/08 e 14/09 do ano de 2002. Para cada avaliação foram usadas cinco vacas entre o $2^{\circ}$ e o $5^{\circ}$ mês de lactação. $O$ registro de dados foi realizado das 18 às 6 h e das 8 às 16h, a cada 10 minutos por dois observadores. Os parâmetros observados foram o tempo de pastejo de capim-elefante, pastejo da aveia, pastejo total (pastejo de capim-elefante mais aveia), ruminação e ócio. A maior intensidade de pastejo ocorreu após as ordenhas, a partir do amanhecer e do anoitecer. Foi verificada posteriormente uma diminuição, tanto durante o dia quanto a noite. O tempo de pastejo diurno foi maior que o noturno. A preferência inicial de pastejo diário foi para a aveia, tanto no início quanto ao final da utilização. O capimelefante foi pastejado em todas as avaliações do período hibernal. O menor tempo de ruminação e o maior tempo de ócio ocorreram no $2^{\circ}$ pastejo devido à maior participação da aveia e menor do capim-elefante na dieta volumosa.

Palavras-chave: aveia, capim-elefante, etologia, pastagens consorciadas.

\section{ABSTRACT}

This work was developed at the Federal University of Santa Maria, RS, Brazil and its objective was to evaluate the behavior of lactating Holstein cows on a pasture constituted by elephantgrass (Pennisetum purpureum Schum.) and black oat (Avena strigosa). Four evaluations were taken (characterizing the winter period) on 06/12, 07/17, 08/25 and 09/14 of 2002. Five cows between the second and the fifth lactation month were used for each evaluation. The data were recorded at a 10 min-interval by two observers, from $6 \mathrm{pm}$ until $6 \mathrm{am}$ and from $8 \mathrm{am}$ until 4pm. The time of elephantgrass grazing, oat grazing, total grazing (elephantgrass plus oat grazing), rumination and idle were the parameters observed. The highest intensity of grazing was registered after morning and evening milking, starting from sunrise or from evening. A decrease was observed lately, during the day as well as during the night. Diurnal grazing time was longer than nocturnal. The cows preferred the oat grazing not only in the beginning but also at the end of utilization. The elephantgrass was grazed at all evaluations at the winter period. The smallest rumination and the largest idle times were observed on the $2^{\text {nd }}$ grazing due to the major participation of oat and minor of elephantgrass on roughage diet.

Key words: elephantgrass, ethology, mixed pastures, oat.

\section{INTRODUÇÃO}

O conhecimento dos hábitos de pastejo, do horário das várias atividades, da relação dos animais com a qualidade e quantidade de forragem e com outros fatores do meio, contribui para melhorar o bemestar (GONYOU, 1994) e o desempenho dos animais (FRASER, 1980; POLLI et al., 1995), tanto em sistemas confinados (CAMARGO, 1988) quanto naqueles baseados em pastagens (BRÂNCIO et al., 2003).

Dentre os fatores que afetam o comportamento dos bovinos, destacam-se o clima, a alimentação e o sistema de produção adotado (GRANT

${ }^{1}$ Departamento de Zootecnia, Universidade Federal de Santa Maria (UFSM), Faixa Nova de Camobi, km 09, Campus Universitário, 97105-900, Santa Maria, RS, Brasil. Email: clairo@ccr.ufsm.br. Autor para correspondência.

${ }^{2}$ Programa de Pós-graduação em Zootecnia, UFSM, Santa Maria, RS, Brasil.

${ }^{3}$ Departamento de Zootecnia, UFSM, Santa Maria, RS, Brasil. 
\& ALBRIGHT, 1995). Para as vacas em lactação, a produção, o horário e o número de ordenhas são condições determinantes em seus padrões de comportamento. As principais variáveis comportamentais estudadas têm sido aquelas relacionadas com as atividades de alimentação, ruminação, ócio e procura por água (RAY \& ROUBICEK, 1971; CAMARGO, 1988).

A ingestão pode englobar as atividades de procura por alimento, seleção, apreensão, mastigação e deglutição do bolo alimentar (FISCHER et al., 2002). O tempo disponibilizado para o consumo de alimentos varia de 4 a 10 horas por dia (FRASER, 1980; PIRES et al., 2001), sendo mais intenso após as ordenhas (ALBRIGHT, 1993).

Sob condições de pastejo, durante o inverno, as vacas apresentam um comportamento típico com picos de alimentação ao amanhecer e ao entardecer, seguido de pequenas variações durante o dia, sendo maiores no turno da noite (FRASER, 1980; BALOCCHI et al., 2002). Nessas condições, ALBRIGHT (1993) observa que normalmente são verificados seis ciclos de pastejo por dia, sendo quatro entre as ordenhas da manhã e da tarde e dois à noite.

O animal em pastejo está sob o efeito de muitos fatores que influem no consumo de forragem. Dentre estes, sobressai a oportunidade de o animal selecionar a dieta, consumindo prioritariamente as folhas mais novas, seguido das mais velhas e dos caules (STOBBS, 1978). Em forrageiras tropicais a massa de forragem torna-se mais fibrosa, reduzindo a sua qualidade mais rapidamente que a das temperadas, podendo haver limitação do consumo (STOBBS, 1973).

A atividade de ruminação em animais adultos ocupa 8 horas por dia com variações entre $4 \mathrm{e}$ 9 horas, divididas em 15 a 20 períodos (FRASER, 1980; VAN SOEST, 1994). Esse comportamento é influenciado pela natureza da dieta e parece ser proporcional ao teor de parede celular dos alimentos volumosos (VAN SOEST, 1994). Entretanto, WELCH \& HOOPER (1982) afirmam que o aumento de fibra indigestível não incrementa a ruminação por mais de 9 horas/dia. Já o ócio e as atividades que não incluem a alimentação e ruminação perfazem cerca de 10 horas (CAMARGO, 1988; ALBRIGHT, 1993), com variações entre 9 e 12 horas por dia (FRASER, 1980; ORR et al., 2001; PHILLIPS \& RIND, 2001).

Em sistemas de produção de leite orgânico ou agroecológico que têm, como parte de suas premissas, a liberdade de escolha dos animais e a diversidade de espécies na formação dos pastos, o estudo do comportamento animal é importante na avaliação de pastagens. A presença, muitas vezes, de espécies de ciclos diferentes, poderá influenciar o comportamento dos animais pela procura de forrageiras palatáveis e que atendam suas necessidades nutricionais. Em função da escolha alimentar, aspectos como a perenidade, a viabilidade da consorciação, o tempo de utilização e a qualidade da forrageira devem ser considerados.

Assim, o objetivo geral do presente trabalho foi estudar o comportamento de vacas em lactação em pastagem constituída por capim-elefante e aveia, manejada sob princípios agroecológicos. Especificamente foram avaliados os tempos de pastejo, ruminação e ócio no decorrer do dia e em períodos representativos do período hibernal. Concomitantemente, analisou-se o tempo de acesso dos animais entre as forrageiras, verificando-se o tempo dedicado para o consumo do capim-elefante e da aveia, avaliando-se o potencial destas culturas no sistema forrageiro proposto.

\section{MATERIAL E MÉTODOS}

O trabalho foi conduzido no município de Santa Maria, na região da Depressão Central do RS, situada a $29^{\circ} 43^{\prime}$ de latitude Sul e 5342' de longitude Oeste. O clima da região é o Subtropical Úmido (MORENO, 1961). A pesquisa foi conduzida em pastagem manejada sob princípios agroecológicos, dos quais os mais importantes foram: cultivo mínimo, adubação orgânica, consorciação de culturas, proteção aos recursos naturais, não uso de biocidas e fertilizantes químicos e os cuidados com o bem-estar dos animais. $\mathrm{Na}$ área experimental, de 0,33 ha, o capim-elefante (CE), cv. Merckeron Pinda, foi estabelecido em outubro de 2001, em linhas afastadas de 3 metros. Nas entrelinhas, estabeleceu-se a aveia, cv. Preta comum. A pastagem foi adubada, no decorrer do ano, com $100 \mathrm{~kg} \mathrm{ha}^{-1}$ de N, sendo $70 \%$ com chorume de suínos e $30 \%$ com esterco bovino (coletado de mangueira de espera, armazenado e coberto com lona).

No presente estudo, foram efetuadas quatro avaliações (épocas de pastejo), nos meses de junho, julho, agosto e setembro de 2002. Os pastejos foram iniciados quando a aveia apresentava cerca de $20 \mathrm{~cm}$ de altura, retirando-se os animais quando esta apresentava cerca de $10 \mathrm{~cm}$ de altura. O primeiro pastejo foi iniciado em 12/06 e o último, em 14/09. A condução de pastejo foi o rotativo, com o tempo dos ciclos de pastejo variando de 29 a 51 dias e o tempo de ocupação foi de um dia.

Para o experimento, utilizaram-se, em cada avaliação, cinco vacas da raça Holandesa entre o $2^{\mathrm{o}} \mathrm{e}$ 
o $5^{\circ}$ mês de lactação, oriundas do rebanho pertencente ao Departamento de Zootecnia - UFSM, com peso médio inicial de $531,87 \pm 52,37 \mathrm{~kg}$ e produção média de $16,67 \pm 2,72$ litros vaca $^{-1} \mathrm{dia}^{-1}$, as quais recebiam, depois das ordenhas, $7,1 \mathrm{~kg}$ de matéria seca como complementação alimentar, sendo $3,5 \mathrm{~kg}$ de concentrado com $20 \%$ de proteína bruta e $3,6 \mathrm{~kg}$ de silagem de milho vaca ${ }^{-1} \mathrm{dia}^{-1}$. Os animais tiveram livre acesso à pastagem e à água durante as observações. Entre as épocas de avaliação, os animais foram mantidos sob mesmo manejo alimentar (complementação alimentar e pastagem da época).

Os parâmetros avaliados, seguindo-se a orientação de CASTRO (2002), foram: tempo despendido com pastejo de aveia (PA), pastejo do CE (PC), pastejo total (CE mais aveia - PCA), ruminação $(\mathrm{R})$ e ócio $(\mathrm{O})$. As observações, realizadas em turnos de quatro horas, foram feitas por dois avaliadores de forma instantânea, a cada 10 minutos, o que não compromete a veracidade dos dados (SALLA et al., 2003). Os parâmetros comportamentais foram registrados, num total de 20 horas diárias, das 18 às 06 e das 08 às 16 horas. Nas quatro horas restantes, as vacas foram retiradas da pastagem, duas vezes ao dia, para as ordenhas da manhã e tarde, quando também receberam a complementação alimentar no cocho.

Para determinação da disponibilidade e da composição botânica da pastagem foram efetuadas amostragens (cortes a $50 \mathrm{~cm}$ do solo para o CE e rente ao solo para a aveia), entre 6 e 8 horas antes da entrada dos animais na área experimental. Para estudar a qualidade da pastagem, retiraram-se, em cada avaliação, amostras de simulação de pastejo (EUCLIDES et al., 1992), na entrada e saída dos animais da pastagem, as quais foram secadas, moídas e posteriormente analisadas para determinação do teor de proteína bruta (PB), digestibilidade in vitro da matéria seca (DIVMS) e fibra em detergente neutro (FDN) pelo método de GOERING \& VAN SOEST (1970).

O delineamento experimental utilizado foi o inteiramente casualizado com quatro tratamentos (épocas de pastejo) e cinco repetições (vacas). Os dados coletados de cada parâmetro foram submetidos à análise de regressão com auxílio do programa estatístico SAS (1997). O modelo matemático utilizado para o delineamento foi o seguinte: $Y i j=m+t_{i}+e_{i j}$ em que, Yij são as variáveis dependentes; i é o índice dos pastejos; $m$ é a média geral; $\mathrm{t}_{\mathrm{i}}$ é o efeito das épocas de pastejo e, e e é o resíduo. O modelo matemático para a análise de regressão polinomial foi o seguinte: Yij $=b_{0}+b_{1} X_{i j}+e_{i j}$ em que, Yij são as variáveis dependentes; $b_{0}$ é a constante da equação; $b_{1}$ é o coeficiente de regressão; $X_{\mathrm{ij}}$ são as épocas de pastejo (dias) e, e $e_{\mathrm{ij}}$ é o resíduo aleatório.

\section{RESULTADOS E DISCUSSÃO}

Os resultados dos parâmetros comportamentais das vacas em lactação, durante o período hibernal, encontram-se na tabela 1 e nas figuras 1 e 2 . O tempo médio de pastejo, por 20 horas, nas quatro avaliações foi de $39,58 \%$ ( $7 \mathrm{~h}$ e $55 \mathrm{~min}$ ), semelhante ao valor encontrado por PIRES et al. (2001), em 24 horas, de 32,5\% (7h e 48min). PHILLIPS \& RIND (2001), trabalhando com vacas da raça holandesa em pastejo de azevém perene, por 24 horas, encontraram $33,95 \%$ ( $8 \mathrm{~h}$ e $9 \mathrm{~min})$. ORR et al. (2001) observaram tempo de pastejo de $32,08 \%$ (7h e $42 \mathrm{~min}$ ), em 24 horas.

Observa-se que o tempo destinado ao pastejo de aveia foi inicialmente menor (Tabela 1). Essa é uma condição típica de uso dessa cultura devido à elevada umidade e alta qualidade nos primeiros pastejos (MOREIRA et al., 2002). A presença do capim-elefante na composição da pastagem e o elevado tempo de pastejo verificado demonstra que, para as condições da região Sul, essa cultura representa uma alternativa na estação outonal e no início do inverno (OLIVO, 1994), período este em que, normalmente, ocorrem deficiências de disponibilidade e qualidade de pastagem para o gado leiteiro. Observase que no mês de junho a relação do tempo de pastejo do capim-elefante e da aveia foi de 2,7:1. Nesse período, o capim-elefante apresentava quantidade substancial de lâminas foliares (Tabela 1). Considerando-se que a maior parte do tempo de pastejo foi destinado ao consumo do capim-elefante, os valores estimados de qualidade são considerados elevados. Em julho e agosto, devido às geadas cumulativas (10) ocorridas e o consequiente crestamento das folhas do capimelefante, o tempo de pastejo foi dedicado para o consumo da aveia (Figura 1). Observa-se que, em agosto, o capim-elefante possuía apenas $0,03 \%$ de lâminas foliares (verdes), correspondendo à maior porcentagem de material morto de todo período hibernal. Analisando-se o tempo de pastejo total (Tabela 1) em setembro, este apresentou efeito significativo (Figura 1) em relação aos demais períodos. Isso se justifica pela maturação da aveia e presença de material senescente entre as brotações das touceiras do capim-elefante, fato esse que se comprova pelo acúmulo de material morto (Tabela 1). Esta condição da pastagem fez com que as vacas dedicassem mais tempo para selecionar sua dieta, o que pode ser constatado pelo menor tempo de ócio, 
Tabela 1 - Tempo utilizado pelas vacas em lactação (\%), em 20h diárias, nas atividades de ruminação (R), ócio (O), pastejo de aveia (PA), pastejo de capim-elefante (PC), pastejo total (pastejo de capim-elefante + aveia - PCA), pastejo diurno (PD) e pastejo noturno (PN) e valores médios dos componentes botânicos do capim-elefante (CE) e da aveia (AV), da qualidade da pastagem (colhida por simulação de pastejo) e dados sobre as condições ambientais, Santa Maria, RS, 2002.

\begin{tabular}{|c|c|c|c|c|c|c|}
\hline \multirow{2}{*}{ Parâmetros comportamentais } & \multicolumn{4}{|c|}{ Tratamentos } & \multirow{2}{*}{ Média } & \multirow{2}{*}{ Coeficiente de variação } \\
\hline & $12 / 06$ & $17 / 07$ & $25 / 08$ & $14 / 09$ & & \\
\hline $\mathrm{R}$ & 43,158 & 34,309 & 41,639 & 40,826 & 39,983 & 9,66 \\
\hline $\mathrm{O}$ & 17,193 & 32,845 & 23,114 & 8,430 & 20,395 & 20,27 \\
\hline PA & 10,702 & 30,569 & 23,935 & 27,273 & 23,119 & 16,00 \\
\hline $\mathrm{PC}$ & 28,947 & 2,277 & 11,311 & 23,471 & 16,501 & 29,49 \\
\hline PCA & 39,649 & 32,846 & 35,246 & 50,744 & 39,621 & 6,00 \\
\hline PD & 57,885 & 72,304 & 52,982 & 53,707 & 59,22 & - \\
\hline $\mathrm{PN}$ & 42,115 & 27,696 & 47,018 & 46,293 & 40,78 & - \\
\hline \multicolumn{7}{|l|}{ Componentes botânicos (\%) } \\
\hline L. Foliar (CE) & 24,68 & 9,40 & 0,03 & 26,34 & 15,11 & - \\
\hline Colmo (CE) & 66,32 & 67,04 & 72,63 & 56,78 & 65,69 & - \\
\hline Material morto (CE) & 9,00 & 23,56 & 27,34 & 16,88 & 19,19 & - \\
\hline L. Foliar (AV) & 69,65 & 50,57 & 41,77 & 14,75 & 44,18 & - \\
\hline Colmo (AV) & 25,00 & 38,11 & 37,12 & 62,92 & 40,78 & - \\
\hline Material morto (AV) & 5,35 & 11,32 & 21,11 & 22,33 & 15,02 & - \\
\hline \multicolumn{7}{|c|}{ Disponibilidade da pastagem $\left(\mathrm{kg} \mathrm{ha}^{-1}\right.$ de MS) } \\
\hline $\mathrm{CE}$ & 3.580 & 2.836 & 1.523 & 2.388 & 2.581 & - \\
\hline AV & 100 & 640 & 994 & 1.033 & 691 & - \\
\hline $\mathrm{CE}+\mathrm{AV}$ & 3.680 & 3.476 & 2.517 & 3.421 & 3273 & - \\
\hline \multicolumn{7}{|l|}{ Qualidade da pastagem (\%) } \\
\hline PB & 18,45 & 18,07 & 14,98 & 14,22 & 16,43 & - \\
\hline FDN & 54,32 & 45,05 & 61,49 & 64,67 & 56,38 & - \\
\hline DIVMS & 70,17 & 65,57 & 61,89 & 60,30 & 64,48 & - \\
\hline \multicolumn{7}{|l|}{ Condições ambientais } \\
\hline $\mathrm{N}^{\circ}$. de geadas cumulativas & 3 & 10 & 11 & 13 & - & - \\
\hline Temperatura ${ }^{\circ} \mathrm{C}$ média/mensal & 13,9 & 13,4 & 16,2 & 15,4 & - & - \\
\hline Temperatura ${ }^{\circ} \mathrm{C}$ média no dia & 9,4 & 10,92 & 27,28 & 14,76 & - & - \\
\hline Temperatura ${ }^{\circ} \mathrm{C}$ máxima no dia & 13,6 & 15,4 & 34,0 & 20,8 & - & - \\
\hline Temperatura ${ }^{\circ} \mathrm{C}$ mínima no dia & 7,4 & 9,0 & 23,8 & 10,4 & - & - \\
\hline Umidade Relativa do $\operatorname{Ar}(\%)$ no dia & 86,25 & 85,25 & 63,75 & 79,25 & - & - \\
\hline Insolação (min) no dia & 361 & 324 & 600 & 594 & - & - \\
\hline
\end{tabular}

$\mathrm{PB}=$ proteína bruta; FDN = fibra em detergente neutro; DIVMS = digestibilidade in vitro da matéria seca.

com efeito significativo, em relação aos demais períodos.

Os dados de comportamento diário dos animais, agrupados a cada duas horas, podem ser observados na figura 2. Observa-se que o turno em que as vacas dedicaram maior tempo ao pastejo foi o diurno (período compreendido entre 8 e 16h) com média de $59,22 \%$ ( $4 \mathrm{~h}$ e $41 \mathrm{~min}$ ) para as quatro avaliações. Este comportamento está dentro do previsto para climas temperados (PIRES et al., 2001). Estes autores verificaram um valor de $65,2 \%$ ( $5 \mathrm{~h}$ e $5 \mathrm{~min}$ ) para o pastejo diurno (período compreendido entre 6 e 17h), semelhante ao encontrado por ALBRIGHT (1993) com cerca de 66\%. Os valores, no entanto, são inferiores aos encontrados por BALOCCHI et al. (2002). O tempo de pastejo noturno representou 40,78\% (3h e 13min), sendo superior ao encontrado por PIRES et al. (2001) que verificaram $34,6 \%$ ( $2 \mathrm{~h} \mathrm{e} 42 \mathrm{~min}$ ) e por BALOCCHI et al. (2002) que observaram valores entre 16,6 ( $1 \mathrm{~h}$ e $14 \mathrm{~min}$ ) e $12,8 \%$ ( $1 \mathrm{~h} \mathrm{e} 3 \mathrm{~min}$ ).

Observa-se que, após a ordenha da manhã, foi registrada a maior atividade de pastejo ("ápice do pastejo"), sucedida por outras de menor intensidade (Figura 2), fato este que é típico de animais sob condições de pastejo em clima temperado (BRÂNCIO et al., 2003). Semelhante comportamento pode ser observado, com menor intensidade, após a ordenha 


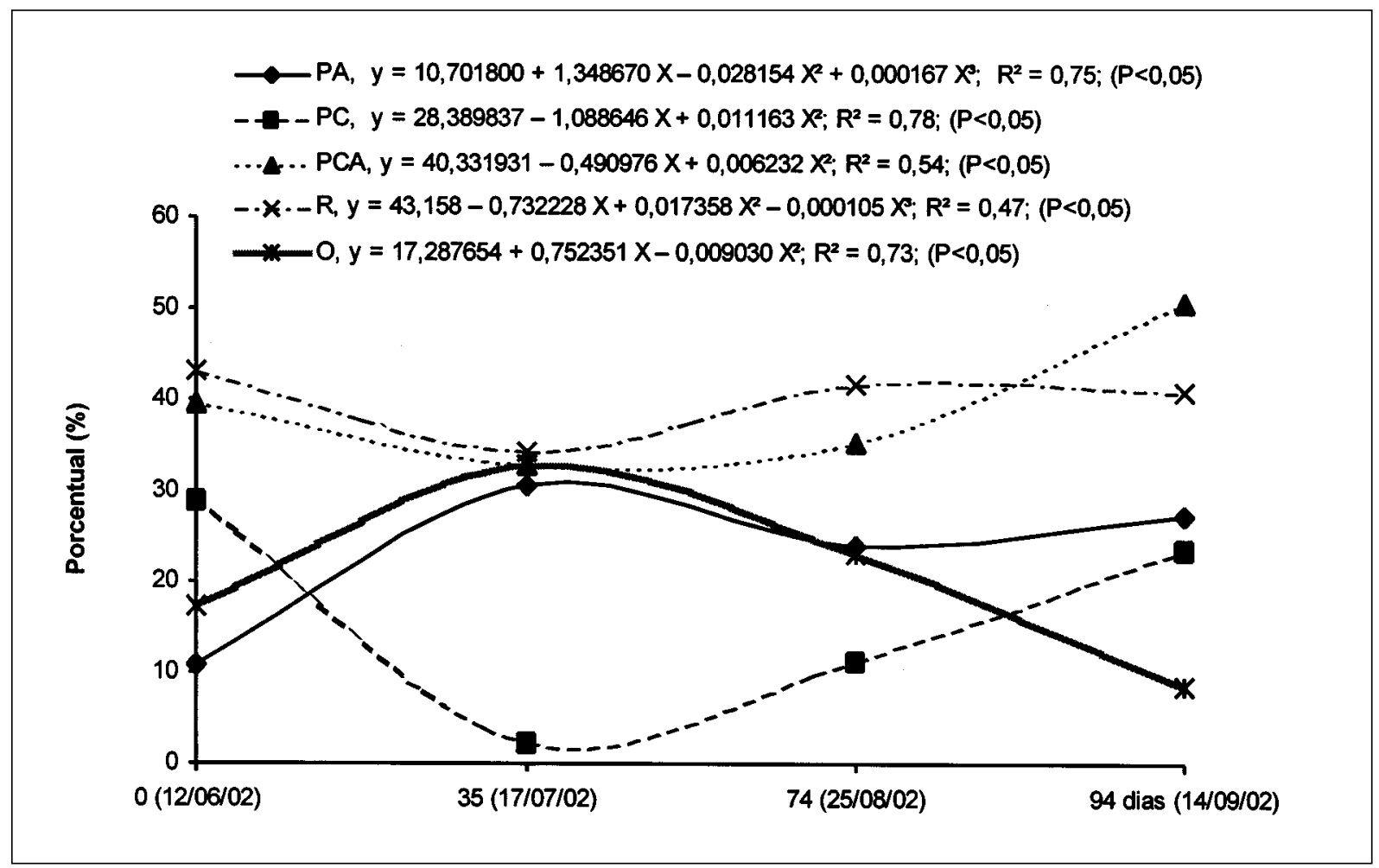

Figura 1 - Dados porcentuais dos parâmetros tempo de pastejo de aveia (PA), tempo de pastejo do capim-elefante (PC), tempo de pastejo total (soma do tempo de pastejo do capim-elefante e aveia - PCA), ruminação (R) e ócio (O) de vacas em lactação da raça Holandesa. Santa Maria, RS.

da tarde. Durante o dia, após o ápice de consumo observado entre 8 e $10 \mathrm{~h}$, verificaram-se picos menores de consumo entre 10 e $16 \mathrm{~h}$. Também após o ápice de consumo ocorrido ao entardecer, entre 18 e $20 \mathrm{~h}$, verificaram-se picos de pastejo de menor intensidade diferenciados entre as épocas avaliadas. No mês de julho, quando os animais utilizaram basicamente aveia, verificou-se um pastejo secundário entre as 24 e $2 \mathrm{~h}$. Já nas demais épocas avaliadas, as vacas pastejaram em diferentes horários da noite. Este comportamento está nitidamente associado à maior participação do capim-elefante na dieta das vacas e o conseqüente aumento no teor de fibra da dieta (Tabela 1). No mês de agosto, verificou-se uma antecipação do pastejo, com diminuição à tarde (entre as 12 e 16h), e aumento no período noturno, das 2 às 6 h, (Figura 2), devido à alta temperatura observada no dia (Tabela 1).

O estudo demonstrou também que a preferência inicial dos animais no pastejo diário foi para a aveia, sendo que o tempo de utilização variou em cada período. O capim-elefante foi pastejado em todos os períodos mesmo em agosto quando apresentava menos de $1 \%$ de lâminas foliares (verdes), o que não comprometeu seu desenvolvimento posterior. Observa-se que esse comportamento ingestivo deu-se voluntariamente com os animais disponibilizando $6,9 \%$ do tempo de pastejo para o capim-elefante (Tabela 1). É provável que os animais tenham equilibrado sua dieta com material mais fibroso (VAN SOEST, 1994) oriundo do capimelefante. Este comportamento ingestivo foi mais típico no mês de julho. Em junho, período em que a aveia apresenta elevado teor de umidade e baixo teor de fibra, e o capim-elefante ainda apresenta razoável qualidade de forragem (OLIVO, 1994), houve predominância no tempo disponibilizado para a cultura de estação quente. No final da avaliação (setembro), verificou-se um aumento no tempo de pastejo (Figuras 1 e 2) e equilíbrio na preferência de consumo das duas forrageiras devido ao aumento no teor de fibra (Tabela 1) tanto da aveia quanto do capim-elefante.

Com relação aos demais parâmetros avaliados, o tempo alocado pelas vacas para ruminação foi o mais estável, sendo menor na $2^{\mathrm{a}}$ avaliação (com cerca de $6 \mathrm{~h}$ e $30 \mathrm{~min} /$ dia para as 20 horas avaliadas) devido à maior participação da aveia na dieta volumosa (Tabela 1 e Figura 1). Nos demais períodos, o tempo de ruminação variou de 40,8 ( 8 h e $10 \mathrm{~min}$ ) a $43,1 \%$ ( $8 \mathrm{~h}$ e 


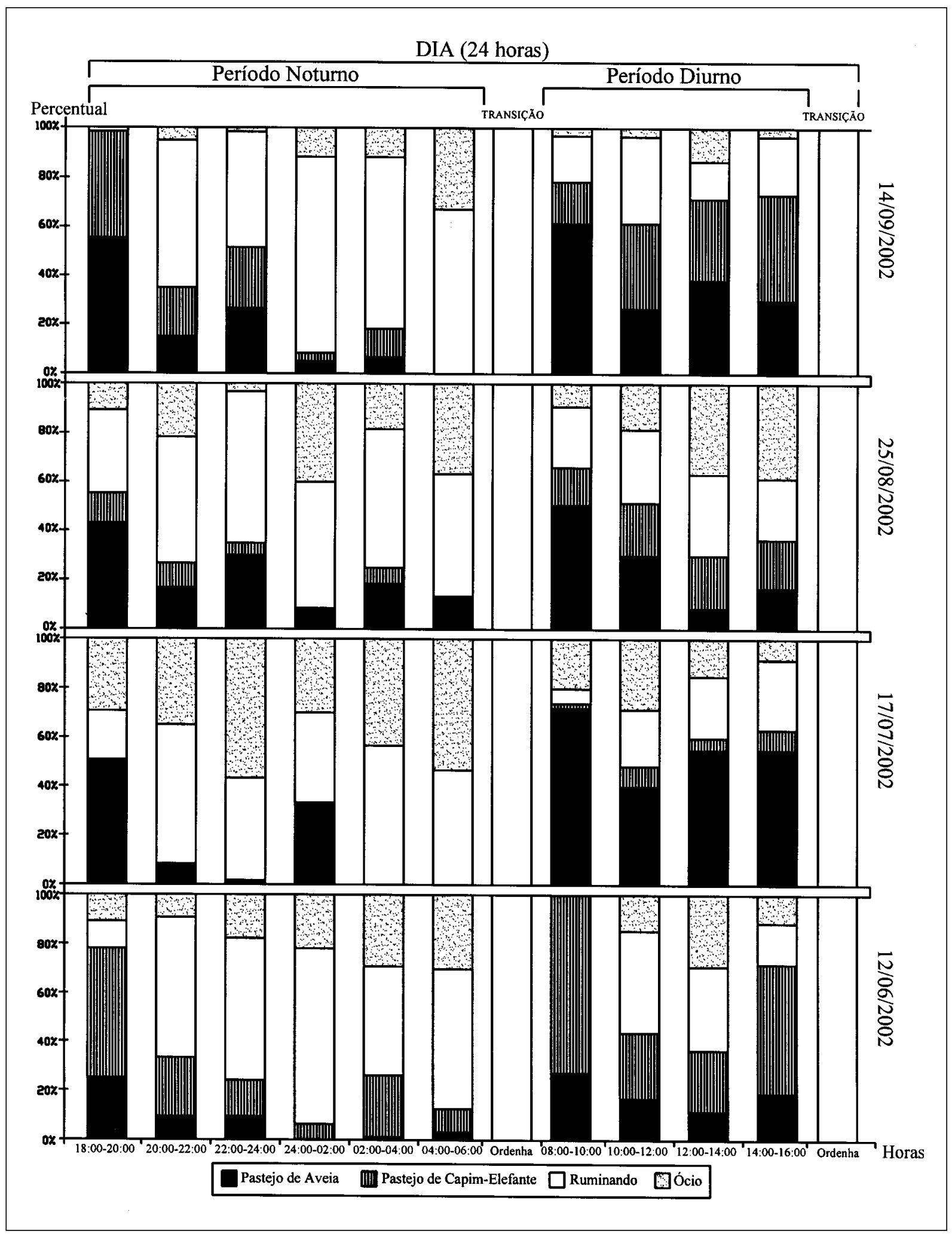

Figura 2 - Tempo médio gasto por vacas em lactação (percentual do tempo em 20 horas) em quatro diferentes momentos da estação hibernal. Dados agrupados em intervalos de duas horas, com os animais usando pastagem de capim-elefante (Pennisetum purpureum) associada com Aveia preta (Avena strigosa). Santa Maria, RS.

Ciência Rural, v.35, n.4, jul-ago, 2005. 
37min) não havendo diferença significativa entre eles ( $\mathrm{P}>0,05)$, sendo superiores aos encontrados por BALOCCHI et al. (2002) que observaram variação de 30,5 (7h e $20 \mathrm{~min}$ ) a $31,7 \%$ (7h e $37 \mathrm{~min}$ ) para esta atividade. $\mathrm{O}$ tempo de ruminação encontra-se na faixa de 4 a 9 horas/dia, normalmente verificada em bovinos (FRASER, 1980; VAN SOEST, 1994). Nos pastejos em que há maior participação do capim-elefante, o tempo de ruminação é mais elevado, não ultrapassando, no entanto, o limite de 9 horas dia $^{-1}$ apontado por WELCH \& HOOPER (1982). A atividade de ruminação foi maior durante a noite, concentrando-se, principalmente, entre as $24 \mathrm{e} 6 \mathrm{~h}$.

O tempo médio de ócio para as quatro avaliações foi de $20 \%$ (4h), sendo inferior aos 38,68\% (9h e $17 \mathrm{~min}$ ) observados por PHILLIPS \& RIND (2001) e aos $37,84 \%$ ( $9 \mathrm{~h}$ e $5 \mathrm{~min}$ ) verificados por ORR et al. (2001) nas $24 \mathrm{~h}$ do dia. O maior tempo de ócio ocorreu em julho, período em que os animais pastejaram basicamente a aveia $(93,1 \%)$. O baixo tempo de ócio verificado na 4a avaliação em relação às demais, deve-se à maturação da aveia e à necessidade de os animais selecionarem as brotações do capimelefante envolvidas com material senescente. Essa assertiva pode ser constatada pelo elevado teor de fibra em detergente neutro $(64,67 \%)$ da dieta selecionada verificada nessa época (Tabela 1).

\section{CONCLUSÕES}

Os ápices de consumo ocorreram após as ordenhas, a partir do amanhecer e do anoitecer, verificando-se picos de pastejo menores, tanto durante o dia quanto à noite.

A preferência inicial dos diferentes ciclos de pastejo, verificados no decorrer do dia, foi para a aveia. Independentemente das épocas avaliadas, típicas do período hibernal, os animais pastejaram o capim-elefante.

O menor tempo de ruminação e o maior tempo de ócio estão associados à maior participação da aveia e menor do capim-elefante na dieta volumosa das vacas.

\section{REFERÊNCIAS}

ALBRIGHT, J.L. Nutrition and feeding calves: Feeding behavior of dairy cattle. Journal of Dairy Science, v.76, n.2, p.485498, 1993.

BALOCCHI, O. et al. Comportamiento de vacas lecheras en pastoreo com y sin suplementación com concentrado. Agricultura Técnica, v.62, n.1, p.87-98, 2002.

BRÂNCIO, P.A et al. Avaliação de três cultivares de Panicum maximum Jacq. sob pastejo: comportamento ingestivo de bovinos. Revista Brasileira de Zootecnia, v.32, n.5, p.1045-1053, 2003.

CAMARGO, A.C. Comportamento de vacas da raça Holandesa em confinamento do tipo "free stall", no Brasil Central. 1988. 146f. Dissertação (Mestrado em Zootecnia) - Curso de Pós-graduação em Zootecnia, Fundação de Estudos Agrários Luiz de Queiroz.

CASTRO, C.R. de C. Relações planta-animal em pastagem de milheto (Pennisetum americanum (L.) Leeke) manejada em diferentes alturas com ovinos. 2002. $185 \mathrm{f}$. Dissertação (Mestrado em Zootecnia) - Curso de Pós-graduação em Zootecnia, Fundação de Estudos Agrários Luiz de Queiroz.

EUCLIDES, V.P.B. et al. Avaliação de diferentes métodos de amostragens sob pastejo. Revista Brasileira de Zootecnia, v.21, n.4, p.691-702, 1992.

FISCHER, V. et al. Padrões da distribuição nictemeral do comportamento ingestivo de vacas leiteiras, ao início e ao final da lactação, alimentadas com dieta à base de silagem de milho. Revista Brasileira de Zootecnia, v.31, n.5, p.2129$2138,2002$.

FRASER, A.F. Comportamiento de los animales de la granja. Zaragoza : Acribia, 1980. 291p.

GOERING, H.K.; VAN SOEST, P.J. Forage fiber analyses, apparatus, reagents, procedures and some applications (Agricultural Handbook). Washington, DC : USDA. 1970. $379 \mathrm{p}$.

GONYOU, H.W. Why the study of animal behavior is associated with the animal welfare issue. Journal of Animal Science, v.72, n.8, p.2171-2177, 1994.

GRANT, R.J.; ALBRIGHT, J.L. Feeding behaviour and management factors during the transition period in dairy cattle. Journal of Animal Science v.73, n.9, p.2791-2803, 1995.

MOREIRA, F.B. et al. Composição química e digestibilidade in vitro da aveia preta, sob pastejo contínuo, no inverno. In: REUNIÃO ANUAL DA SOCIEDADE BRASILEIRA DE ZOOTECNIA, 39., 2002, Recife, PE. Anais... Recife : Sociedade Brasileira de Zootecnia, 2002. (CD - ROOM).

Moreno, J.A. Clima do Rio Grande do Sul. Porto Alegre : Secretaria da Agricultura, 1961. 41p.

OLIVO, C.J. Avaliação da preferência de cultivares de capimelefante pastejados por vacas em lactação. Lavoura Arrozeira, Porto Alegre, v.47, n.415, p.26-30, jul-ago, 1994.

ORR, R.J.S. et al. Matching grass supply to grazing patterns for dairy cows. Grass and Forage Science, v.56, n.35, p.352-361, 2001.

PHILLIPS, C.J.; RIND, M.I. The effects of social dominance on the production and behavior of grazing dairy cows offered forage supplements. Journal of Dairy Science, v.85, n.1, p.51-59, 2001 .

PIRES, M. de F.A. et al. Comportamento alimentar de vacas holandesas em sistemas de pastagens ou em confinamento. Minas Gerais : EMBRAPA Gado de Leite, 2001. 2p. (Boletim Técnico, 2). 
POLLI, V.A. et al. Comportamento de bovinos e bubalinos em regime de confinamento. I Atividades. Ciência Rural, v.25, n.1, p.127-131, 1995.

RAY, D.E.; ROUBICECK, C.B. Behaviour of feedlot cattle during two seasons. Journal of Animal Science, v.33, n.1, p.46-51, 1971.

SALLA, L.E. et al. Comportamento ingestivo de vacas jersey alimentadas com dietas contendo diferentes fontes de gordura nos primeiros 100 dias de lactação. Revista Brasileira de Zootecnia, v.32, n.3, p.683-689, 2003.

SAS Statistical Analisysis System User's Guide. Stat, 2.ed. Cary : SAS Institute, 1997. 456p.

STOBBS, T.H. The effect of plant structure on the intake of tropical pasture. 2. Differences in sward structure, nutritive value, and bite size of animals grazing Setaria anceps and Chloris gayana at various stages of growth. Australian Journal of Agricultural Research, v.24, n.6, p.821-829, 1973.

STOBBS, T.H. Milk production, milk composition, rate of milking and grazing behavior of dairy cows grazing two tropical grass pasture under a leader and follower systems. Australian Journal of Experimental Agriculture and Animal Husbandry, v.18, n.1, p.5-11, 1978.

VAN SOEST, P.J. Nutritional ecology of the ruminant. Cornel : Ithaca, 1994. 476p.

WELCH, J.G.; HOOPER, A.P. Ingestion de alimentos y agua. In: CHURCH, D.C. El rumiante: fisiologia digestiva y nutrición. Zaragoza : Acribia, 1982. Cap.5, p. $117-126$. 